\title{
FURTHER COMPARISON OF ON-CAMPUS VS. E-LEARNING STUDENT SUCCESS FOR AN IS COURSE
}

\author{
Roy O. Foreman, Purdue University Calumet, foreman@purduecal.edu
}

\begin{abstract}
Today's economic climate continues to favor budget cuts and a close watch on resources. The popularity of distance education/eLearning classes continues to grow in both State and private institutions of higher learning. These courses are convenient for students and provide a very economical way for institutions to deliver courses. It is true that many students do, in fact, succeed in these courses, but a significant number do not. Maturity may play a roll, and freshman and sophomore level students are not always prepared as well as upper-level or graduate students to handle the discipline required for eLearning. In a very popular computer literacy class offered at Purdue University Calumet, it continues to appear that grade point averages and success rates are lower for students in eLearning sections. In a follow up to previous research, this study analyzes two years' worth of data for all students enrolled in an entry level information systems class.
\end{abstract}

Keywords: eLearning, Distance Education, Distance Learning, Online Education, Information Systems Curriculum

\section{INTRODUCTION}

Student frustration with certain distance education/eLearning classes is well documented [2] and understandable. As students choose, or are sometimes forced to choose, enrollment in distance education/eLearning classes they often face the reality of self-motivation and communications problems. These classes are here to stay and, as with traditional courses, we, as educators, must work hard to improve our methods of delivery. Purdue University Calumet (PUC) has a long history of offering eLearning classes. The current delivery system, Blackboard/Vista, has been in use for several years and seems to offer instructors satisfactory flexibility in presenting material, collecting assignments, administering exams, and reporting grades. Most non-eLearning classes utilize Blackboard/Vista to assist in course delivery. The one thing that cannot be duplicated for the eLearning classes is the in person, face-toface contact that traditional classes offer. Even with the use of videos, the personal touch that face-to-face contact offers cannot be matched. So, could this be a factor in overall success? As pointed out in a limited earlier research paper [4], it appears that it is. Other factors, of course, come into play, but it still appears that the lack of personal bonding between student and teacher is a key component leading to reduced scores in certain eLearning classes. This paper compares and contrasts the semester grades earned by over 1900 students in an introductory information system class over the course of four consecutive semesters.

\section{Computer Literacy Course}

CIS 20400, Introduction to Computer Based Systems, is a course required by every CIS major and satisfies a general education computer literacy requirement for many other majors at PUC. CIS 20400 presents basic computer concepts and terminology. It also provides rigorous introductory labs using Microsoft Office software. The class has been offered many years and, for the last five years has been available in both on-campus and distance education sections. Four recent semesters (Spring, 2010; Fall, 2010; Spring, 2011; and Fall, 2011) are examined in this study.

CIS 20400 has no prerequisites and tends to have slightly more freshmen and sophomores students than juniors and seniors. All students have met university admission requirements and are equally qualified to enter the course. As might be expected, students with considerable computer experience in high school or in the workplace will have an advantage. CIS 20400 is offered through 15 to 17 sections every semester. Although fewer sections are offered, eLearning sections tend to fill first and tend to have greater enrollment figures than the traditional on-campus sections. The figures used in this study come from 64 sections taught over the course of two years. 


\section{Issues in Information Systems \\ Volume 13, Issue 1, pp. 185-189, 2012}

\section{RESEARCH METHODOLOGY}

This study focused on the following research question: Do eLearning students succeed at the same level as their oncampus counterparts?

The research hypotheses are as follows:

$\mathrm{H}_{1}$ : Intended major has no effect on performance in an introductory CIS course.

$\mathrm{H}_{2}$ : Using the same textbook, the same lab assignments, and the same set of exams and quizzes, on-campus and eLearning students should perform at comparable levels.

Last year's limited study evaluated the overall success or failure of students in eLearning sections versus on-campus sections using average percent, median percent, GPA, and median GPA. This study focuses simply on GPA's and takes a look at withdrawal and failure percentages. In both forms of delivery, a student's semester grade is based upon the percent of total points he/she achieves during the semester. Through the use of laboratory assignments, quizzes, and exams, students have the opportunity to add to their point totals. Laboratory assignments are delivered using Pearson's MyITLab software. All students, eLearning or not, use the same assignments. In the last two years the video demonstrations supplied by Pearson have been incorporated into the material provided for all sections. The videos are high quality in nature and seem to be well accepted by the students. Studies have shown this to be a significant factor in student success [3]. Point totals for eLearning sections are the same each semester as point totals for on campus sections. Exams and quizzes are administered via Blackboard/Vista and, likewise, are exactly the same. All exams and quizzes are open book/open note for both groups and are timed. The only significant difference is that eLearning students usually have a 3 or 4-day window in which to take their exams whereas on campus students must complete their exams at a regular class meeting. An advantage for distance learning students might be perceived here in that they can choose the environment in which they ultimately complete the exam or quiz.

Approximately 50\% of all possible points for CIS 20400 come from exams, $40 \%$ from laboratory assignments, and $10 \%$ from quizzes. Students who withdraw from the classes are, of course, not included in the GPA calculations but it is interesting to compare the percent of withdrawals in eLearning vs. on-campus classes (see Table 6) as well as the failure rates (see Table 7).

Table 1 Evaluation Criteria

GPA-4 point scale

A:4.0, A-:3.7, B+:3.3, B:2.0, B-:2.7, C+:2.3, C:2.0, C-:1.7, D+:1.3, D:1.0, D-:0.7, F:0.0

\section{RESULTS}

The results produce some interesting insights. The first hypothesis appears to be supported but further research needs to be completed and prepared for a future paper. The second hypothesis does not seem to be supported. As judged by semester GPAs, the overall trend is for on-campus students to succeed at a slightly higher level than their eLearning counter parts.

The tables that follow present the results. 


\section{Issues in Information Systems}

Volume 13, Issue 1, pp. 185-189, 2012

Table 2 Spring, 2010

CIS 20400 eLearning

\# Students

105

GPA

2.53

CIS 20400 campus

\# Students

387

GPA

2.96

Table 3 Fall, 2010

CIS 20400 eLearning

\# Students $\quad 106$

GPA

2.57

CIS 20400 campus

\# Students 339

GPA 2.70

Table 4 Spring, 2011

CIS 20400 eLearning

\# Students 85

GPA 2.40

CIS 20400 campus

\# Students $\quad 375$

GPA $\quad 2.45$

Table 5 Fall, 2011

\begin{tabular}{lr}
\hline CIS 20400 eLearning & \\
\# Students & 80 \\
GPA & 2.12
\end{tabular}

CIS 20400 campus

\# Students 265

GPA 2.70

To further emphasize differences in eLearning vs. on-campus trends, Tables 6 and 7 present figures for withdrawals and failures in the classes examined in this study. For withdrawals, the original enrollment (Org. Enroll), number of withdrawals, and percent of withdrawals are shown. For failures, the enrollment at the end of the semester (Final Enroll), number of failures, and percent of failures are shown. 


\section{Issues in Information Systems}

Volume 13, Issue 1, pp. 185-189, 2012

Table 6 Withdrawals per semester

\begin{tabular}{lcc} 
Course/Semester & $\begin{array}{c}\text { Org. } \\
\text { Enroll }\end{array}$ & $\begin{array}{c}\text { Withdrawals } \\
\text { \# and \% }\end{array}$ \\
\hline CIS 20400 eLearning & & \\
Spring '10 & 118 & $13-11 \%$ \\
Fall'10 & 124 & $18-15 \%$ \\
Spring '11 s & 101 & $16-16 \%$ \\
Fall '11 & 85 & $5-6 \%$ \\
& & \\
CIS 20400 campus & & \\
Spring '10 & 422 & $35-8 \%$ \\
Fall '10 & 368 & $29-8 \%$ \\
Spring '11 & 408 & $33-8 \%$ \\
Fall '11 & 295 & $30-10 \%$
\end{tabular}

Table 7 Failures per semester

\begin{tabular}{lcc} 
Course/Semester & $\begin{array}{c}\text { Final } \\
\text { Enroll }\end{array}$ & $\begin{array}{c}\text { Failures } \\
\text { \# and \% }\end{array}$ \\
\hline CIS 20400 eLearning & & \\
Spring '10 & 105 & $20-19 \%$ \\
Fall '10 & 106 & $17-16 \%$ \\
Spring '11 & 85 & $14-16 \%$ \\
Fall '11 & 80 & $20-25 \%$
\end{tabular}

CIS 20400 campus

$\begin{array}{lll}\text { Spring '10 } & 387 & 32-8 \% \\ \text { Fall '10 } & 339 & 39-12 \% \\ \text { Spring '11 } & 375 & 59-16 \% \\ \text { Fall '11 } & 265 & 31-12 \%\end{array}$

\section{CONCLUSIONS}

Semester by semester, the data in Tables 2 through 5 clearly shows a difference in the GPAs for eLearning versus on-campus classes. The on-campus students consistently performed at a higher level. Standard deviation calculations show that the results are within the normal range of probability, but the fact that the results are regular from one semester to the next demonstrates a clear difference. The differences may not be alarming enough to produce any sense of emergency in this matter but it certainly points to something that should be watched. Upper lever and graduate level classes may not produce the same results. This whole phenomenon may be unique to this particular class at this particular university. Rather than treating eLearning and on-campus classes exactly the same, perhaps there are some extra additives that need to be mixed into the eLearning environment? Since the differences are not statistically significant maybe there is no problem at all with the class.

Regardless of the statistical significance, this is a matter that seems to be worthy of further investigation. As speculated in the previous study [4], eLearning, by its nature, may amplify a lackadaisical approach to studies on the part of some students. Perhaps we should simply accept the concept that eLearning students, on average, do less well than on-campus students in certain classes.

Turning attention to Tables 6 and 7, other than the anomaly shown in Table 6 for the Fall 2011 semester, clearly the percent of withdrawals is seemingly high for the eLearning sections as compared to the on-campus sections. As shown in Table 7, failure rates also seem to trend higher in the eLearning sections. Percent wise, there is a tie for 


\section{Issues in Information Systems}

Volume 13, Issue 1, pp. 185-189, 2012

the Spring 2011 semester, however the results for Spring 2010 and Fall 2011 show the failure rates being twice as high in the eLearning sections. A student who chooses not to withdraw from a course but at the same time does little or no work for the class (effectively withdrawing without going through the formal process) is going to have an impact on averages whether in an eLearning or on-campus course. Perhaps eLearning students are just more likely not to withdraw, passing or not. This may make an interesting topic for another study.

Admittedly, the eLearning sections of CIS 20400 were developed using 'rapid eLearning' which may account for some unseen flaws in delivery [1]. This too may make and interesting topic for another study.

\section{REFERENCES}

1. Boulet, G. "Rapid eLearning: Building a House Without an Architect", eLearn Magazine, Feb. 2012

2. Capdeferro, N. and Romero, M. "Are Online Learners Frustrated with Collaborative Learning Experiences", The International Review of Research in Open and Distance Learning, Vol. 13, No. 2 (2012)

3. Donkor, F. "Assessment of Learner Acceptance and Satisfaction with Video-Based Instructional Materials for Teaching Practical Skills at a Distance", The International Review of Research in Open and Distance Learning, Vol. 12, No. 5 (2011)

4. Foreman, R. "A Comparison of Success in On-Campus versus Distance Learning for an Information Systems Course, Issues in Information Systems", Vol. 12, Issue 2 (2011) 